УДК 004.942; 004.92

() Я. В. Зоренко, К.т.н., доцент, О. В. Коломієць, магістр, КП। ім. Ігоря Сікорського, Київ, Україна

\title{
ДОСЛІДЖЕННЯ ТЕХНОЛОГІЇ ПІДГОТОВКИ ЗОБРАЖЕНЬ ІЗ РОЗШИРЕНИМ ДИНАМІЧНИМ ДІАПАЗОНОМ ДЛЯ ВЕБ-САЙТІВ
}

В представленій роботі розглянуто проблематику процесу підготовки зображень із розширеним діапазоном (від англ. High Dynamic Range, HDR) для розміщення на сторінках вебсайтів. Як відомо, для забезпечення нормального функціонування веб-сайтів необхідно враховувати вплив великого обсягу інформативності зображень із розширеним динамічним діапазоном. Тому проведені в роботі дослідження HDR-технологій є актуальними та дозволять визначити раціональне відношення візуальної якості до інформативності цифрових зображень, що підвищить функціональність веб-сайтів із HDR-фотографіями.

Ключові слова: фотосайт; HDR; контраст зображення; веб-сайт; RAW; DNG; динамічний діапазон.

\section{Постановка проблеми}

Розвиток сучасних апаратнопрограмних засобів отримання цифрової фотографії (фотокамери, мобільні телефони, планшети та ін.) значно розширив сфери застосування зображень із розширеним динамічним діапазоном (від англ. High Dynamic Range, HDR).

Одним із відносно нових напрямків застосування зображень із розширеним динамічним діапазоном, або HDR-зображень $€$ веб-сайти, що складаються із високоякісних фотографій, для яких важливим $€$ наближеність характеристик цифрових фотографій до реальних об'єктів сюжету фотозйомки. Однак існуючі технології за якістю створених HDR-зображень доволі різняться і не завжди забезпечують достатню деталізацію, роздільну здатність та тоновий діапазон зображень. Також, слід враховувати вплив великого обсягу інформативності HDR-зображень на зниження функціональності веб-сайтів. Тому подальші дослідження HDR-технологій для пошуку раціонального відношення візуальної якості до інформативності цифрових зображень $\epsilon$ доволі перспективними та актуальними.

\section{Аналіз попередніх досліджень}

Сучасний стан технологій створення та відтворення HDR-зображень для різних інформаційнотехнічних комунікаційних систем демонструє стрімке зростання,

(๑) $2018 \mathrm{p}$. 
що підтверджується значною кількістю наукових доробок [1-10]. Зокрема, кількість поданих заявок на патенти за HDRтехнологіями останніми роками має значну динаміку до зростання, а основні напрямки стосуються розробки нових ефективних схем обробки зображень, створення сенсорів у фотокамерах із підвищеною світлочутливістю та удосконалення конструкції пристроїв для створення HDR-зображень [6].

Наукові доробки щодо HDRтехнологій [1-10] стосуються пошуку нових алгоритмів розширення динамічного діапазону для HDR-зображень, створенню алгоритмів стиснення HDR-зображень для зменшення їхнього розміру у Мбайтах, розробки методів конвертації та адаптації HDR-зображень для відображення на LDR-моніторах (від англ. Low Dynamic Range) тощо. Однак доволі незначна кількість досліджень стосується впливу режимів створення HDR-зображень на їхню якість, а також особливостям підготовки HDR-зображень до розміщення на веб-ресурсах, що також $є$ актуальними питаннями при застосуванні HDR-технологій.

Тому було проведено дослідження HDR-технологій підготовки зображень із розширеним динамічним діапазоном до розміщення на веб-ресурсах. Для аналізу основних стадій технології підготовки зображень із розширеним динамічним діапазоном для веб-сайтів було запропоновано алгоритм процесу створення HDR-фотографій для веб-сайту (рис. 1).
Запропонований алгоритм процесу створення HDR-фотографій включає такі послідовні етапи (див. рис. 1):

- налаштування та підготовка фотоапарату до зйомки;

- встановлення раціональних показників діафрагми, витримки та світлочутливості (ISO);

- підготовка «брекетингу» (функція автоматичної зміни режимів експозиції);

- отримання серії RAW-фотографій з різними показниками експозиції;

- процес створення HDR-фотографій за допомогою утиліти Camera RAW програмного забезпечення Adobe Photoshop [11], що включає проміжні етапи: корекцію для мінімізації зсуву фотографій, колірну корекцію, вибір ступеню стиснення для збереження HDR-фотографії у графічний формат JPEG, визначення коефіцієнту якості HDR-фотографії, створення мініатюр HDR-фотографії з раціональними параметрами для веб-ресурсу.

\section{Мета роботи}

Дослідження процесу створення HDR-фотографій із визначенням впливу режимів підготовки фотозйомки на динамічний діапазон фотографії, а також встановлення раціональних параметрів забезпечення візуальної подібності HDR-фотографій при підготовці до публікації їх на веб-ресурсах.

\section{Результати проведених досліджень}

В ході проведеного дослідження технології підготовки HDRфотографій для веб-сайтів із HDR-фотографіями було засто- 
совано фотокамеру Nikon D5100 3 матрицею розміром 23,6×15,6 мм та кількістю пікселів у 16,2 Mpix. Для отримання HDR-фотографій застосувалися різноманітні режими фотозйомки із зміною експозиції $(\Delta \mathrm{Ev})$ в межах від -3 до +3 , а також кроку експозиції (N) та ступеню стиснення фотографії (К). Оцінювання створених HDR-фотографій для веб-

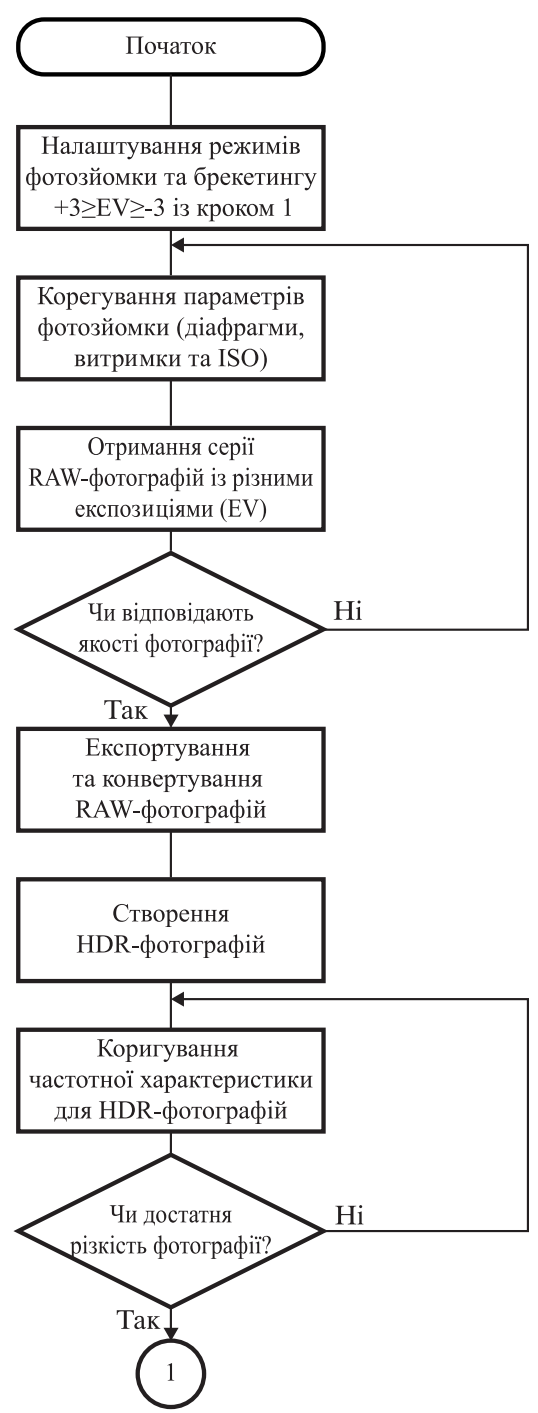

сайтів здійснювалося за відносним показником якості $\left(\mathrm{K}_{\mathrm{g}}\right)$, що розраховувався за усередненою величиною контрасту (гами) в 12-ти локальних градаційних зонах фотографії.

Для створення HDR-фотографій застосовувалося програмне забезпечення Adobe Photoshop та Camera Raw. Статистична обробка результатів дослідження

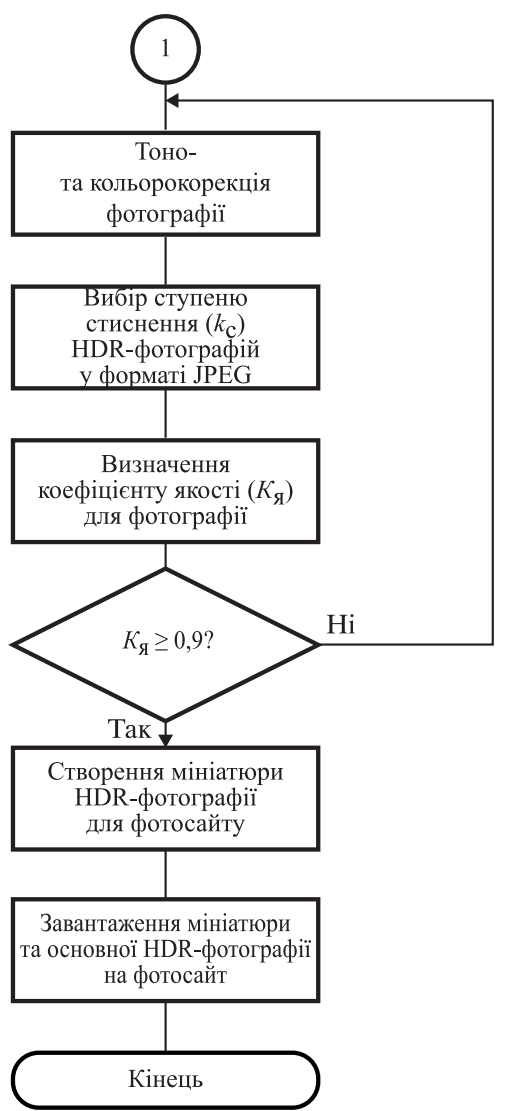

Рис. 1. Алгоритм процесу підготовки HDR-фотографій для веб-сайту 
здійснювалася за допомогою програмного забезпечення MS Excel 2013 та MathCAD 12.

За аналізом експериментальних даних було встановлено характер впливу режимів фотозйомки (діапазону корегування експозиції, кроку експозиції та ступеню стиснення) на відносний показник якості HDR-фотографії (рис. 2-4). Так, встановлено, що зміна кроку експозиції (N) має незначний вплив на кінцеву якість створюваних HDR-фотографій (рис. 2).
Однак, найбільший плив на якість HDR-фотографій має ступінь стиснення (K), що пояснюється його впливом на загальний обсяг файлу HDR-фотографій (рис. 4). Також важливим параметром для процесу створення HDR-фотографій $є$ діапазон корегування експозиції $(\Delta \mathrm{Ev})$, адже він впливає на кількість градацій та загальну деталізацію фотографій (рис. 3).

Також, було визначено вплив HDR-фотографій створених за різними режимами на швидкість

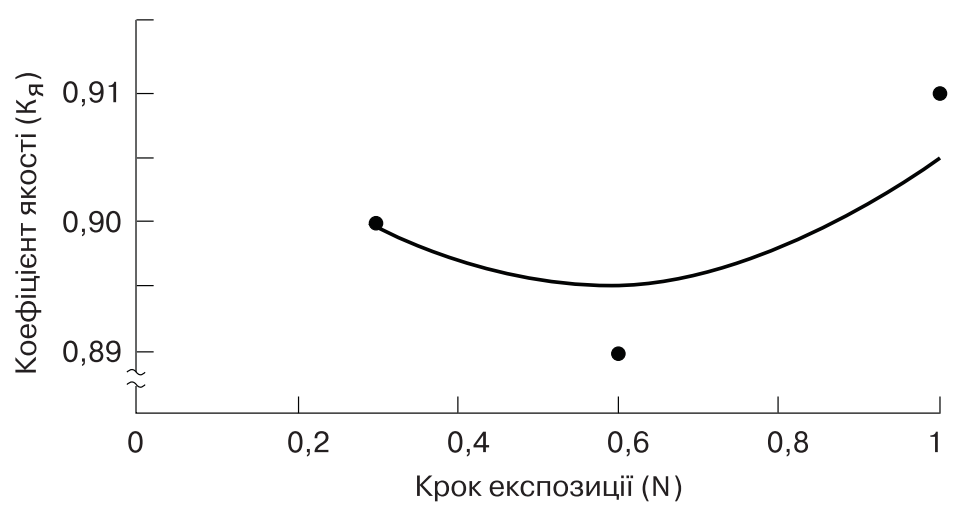

Рис. 2. Залежність показника відносної якості $\left(\mathrm{K}_{g}\right) \mathrm{HDR}$-фотографій від величини кроку експозиції (N)

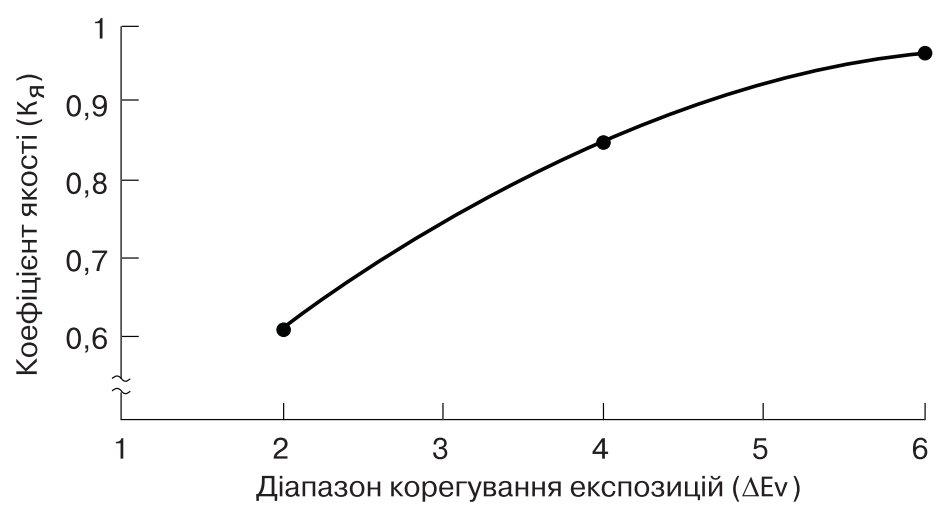

Pис. 3. Залежність показника відносної якості $\left(\mathrm{K}_{я}\right)$ HDR-фотографій від діапазону корегування експозиції ( $\Delta \mathrm{Ev})$ 


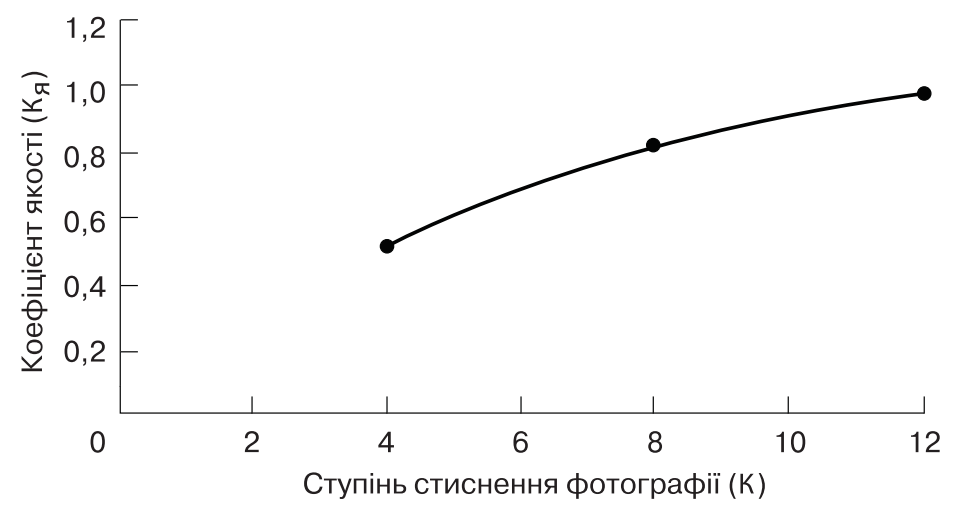

Рис. 4. Залежність показника відносної якості $\left(\mathrm{K}_{я}\right)$ HDR-фотографій від ступеню стиснення фотографії (K)

завантаження сторінок веб-сайту. Причому для визначення швидкості завантаження сторінок веб-сайту було використано браузер Mozilla Firefox. За peзультатами аналізу даних встановлено, що на швидкість завантаження сторінок веб-сайту найбільший вплив має діапазон корегування експозиції та ступінь стиснення фотографії. Причому швидкість завантаження сторінок веб-сайту змінювалася в діапазоні $\mathrm{t}=1-2,5 \mathrm{c}$.
На основі результатів проведеного дослідження технології створення HDR-зображень було побудовано регресійне рівняння другого порядку за допомогою функції «augment», «regress» та «interp» в програмному пакеті MathCAD 12, що дозволило визначити вплив параметрів цифрової фотографії на якість HDRзображення (рис. 5). В результаті застосування регресійного аналізу було отримано залежність типу $Z=f(X, Y)$, де $Z$ - якість

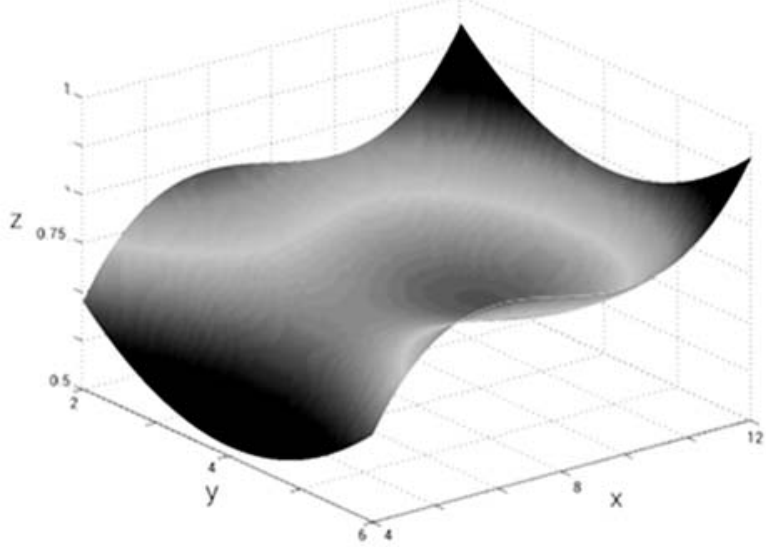

Рис. 5. Зразок графічної залежності $Z=f(X, Y)$ для визначення впливу режимів цифрової фотографії на якість HDR зображення 
HDR-зображення визначеної за точністю градаційної передачі (різниця яскравостей за 12 зонами зображення), X - ступінь стиснення фотографії, що змінюється в діапазоні з 4 до 12 за режимами графічного формату JPEG, Y - діапазон корегування експозицій для фотографії, що змінюється $з 2$ до 6 Ev.

Створена на основі досліджень регресійна модель дозволила визначити раціональні режими підготовки фотографій для створення HDR-зображення із мінімальними втратами якості. Було встановлено найкращу якість за ступеня стиснення JPEG із застосуванням режиму «Quality = 12», а також при діапазоні експозицій Ev $=6$ та $\mathrm{Ev}=4$. Нижча якість створених HDR зображень спостерігалася при параметрах: діапазон корегування експозицій Ev = 2 та при застосуванні стиснення JPEG із режимом починаючи від «Quality = 8» та нижчими значеннями. Також, можна констатувати, що найбільший вплив на якість HDRзображень має показник коригування експозиції, адже при його зростанні, також, підвищується якість створених HDR-зображень.

Отже, на основі проведеного дослідження можна сформувати рекомендації щодо процесу створення HDR-фотографій для вебсайту: для мініатюр фотографій необхідно застосовувати незначну роздільну здатність та великий ступінь стиснення файлу; для прийнятної якості HDR-фотографій потрібно застосовувати максимально можливий показник коригування експозиції із значенням не меншим Ev $=4$; для забезпечення найкращої якості HDR-фотографій при їх роз- міщенні на сторінках веб-сайту необхідно застосовувати ступінь стиснення JPEG із режимом «Quality = 12».

\section{Висновки}

1. Розроблено алгоритм процесу підготовки HDR-фотографій для веб-сайтів, що дозволяє встановити раціональні режими та параметри створення фотографій у графічному форматі RAW для подальшої їх обробки та створення HDR-фотографій.

2. На основі аналізу результатів дослідження встановлено, що найбільший плив на якість HDR-фотографій має ступінь стиснення (K) та діапазон корегування експозиції ( $\Delta \mathrm{Ev})$. Однак, показник зміни кроку експозиції (N) має незначний вплив на кінцеву якість створюваних HDR-фотографій.

3. За результатами аналізу швидкості завантаження сторінок веб-сайту із HDR-фотографіями створеними за різними режимами в межах браузера Mozilla Firefox, встановлено найбільший вплив показника діапазону корегування експозиції та ступеню стиснення фотографії. Причому швидкість завантаження сторінок веб-сайту із різними за режимами створення HDR-фотографіями змінювалася в діапазоні $\mathrm{t}=1-2,5 \mathrm{c}$, що $є$ доволі суттєвим та впливає на зручність користування веб-сайтом в цілому.

4. На основі регресійного аналізу даних дослідження було встановлено, що краща якість HDR-фотографій досягається при застосуванні ступеню стиснення JPEG із режимом «Quality = 12», а також при діапазоні експози- 
цій $\mathrm{Ev}=6$ та $\mathrm{Ev}=4$. Нижча якість створених HDR зображень спостерігалася при параметрах: діапазон корегування експозицій $\mathrm{Ev}=2$ та при застосуванні стиснення JPEG із режимом починаючи від «Quality = 8» та нижчими значеннями

5. На основі результатів проведеного дослідження розроб- лено рекомендації для процесу підготовки HDR-фотографій для сторінок веб-сайту, що дозволяють підібрати режими створення HDR-фотографій із забезпеченням раціонального співвідношення якості та обсягу файлу фотографій і, як наслідок, забезпечення оперативного завантаження всіх сторінок веб-сайту.

\section{Список використаної літератури}

1. Fattal, R., Lischinski, D., \& Werman, M. (2002, July). Gradient domain high dynamic range compression. In ACM transactions on graphics (TOG) (Vol. 21, No. 3, pp. 249-256). ACM. doi: 10.1145/566654.566573.

2. Ward, Greg \& Simmons, Maryann. (2005). JPEG-HDR: a backwards-compatible, high dynamic range extension to JPEG. SIGGRAPH Courses. doi: 10.1145/1185657.1185685.

3. Ward, Greg, Reinhard, Erik, \& Debevec, Paul. (2008). High dynamic range imaging \& image-based lighting. ACM SIGGRAPH 2008 classes. 1-137.

4. Banterle, F., Debattista, K., Artusi, A., Pattanaik, S., Myszkowski, K., Ledda, P. and Chalmers, A. (2009). High Dynamic Range Imaging and Low Dynamic Range Expansion for Generating HDR Content. Computer Graphics Forum, 28: 2343-2367. doi: 10.1111/j.1467-8659.2009.01541.x.

5. Jakubiec, J. Alstan, et al. (2016). Accurate measurement of daylit interior scenes using high dynamic range photography. Proceedings of the CIE 2016 Lighting Quality and Energy Efficiency Conference. Режим доступу: https://www.researchgate.net/publication/305703131.

6. Коломієць О. В. Дослідження тенденцій розвитку технологій створення HDR-зображень // 16 Міжнародна науково-технічна конференція студентів і аспірантів «Друкарство молоде»: збірник тез доповідей. Київ: ВПІ НТУУ КПІ ім. Ігоря Сікорського, 26-28 квітня, 2016. С. 65-66.

7. Зоренко Я. В. Параметри відеосистеми КВС для процесу калібрування / Я. В. Зоренко, Д. О. Сак // Технологія і техніка друкарства. 2014. № 1. C. 21-29. URL: http://ttdruk.vpi.kpi.ua/article/view/31417.

8. Слободян М. О. Профілювання друкувальних пристроїв для підвищен-ня якості кольоровідтворення / М. О. Слободян, О.В.Зоренко, О. Ю. Байдак // Технологія і техніка друкарства. 2015. № 1(47). С. 48-60. URL: http://ttdruk.vpi.kpi.ua/article/view/43275.

9. Зоренко О. В. Стабілізація процесу друкування журнальної продукції / О. В. Зоренко, К. Г. Кириченко, В.М.Скиба // Технологія і техніка друкарства. 2014. № 2(44). С. 35-58. URL: http://ttdruk.vpi.kpi.ua/article/view/31819.

10. Артюшина И. Л. Методы регистрации и воспроизведения высококонтрастных оригиналов в системах с ограниченным динамическим диапазоном / И. Л. Артюшина, Р. Ж. Ахтариев, А. И. Винокур // Технологія і техніка друкарства. 2009. № 3(25). С. 24-30. http://ttdruk.vpi.kpi.ua/article/view/57894. 
11. Посібник користувача Photoshop. Adobe Camera Raw. Adobe Help. Режим доступу: https://helpx.adobe.com/ua/photoshop/userguide.html?topic=/ua/uk/photoshop/morehelp/camera_raw.

\section{References}

1. Fattal, R. \& Lischinski, D. \& Werman, M. (2002, July). Gradient domain high dynamic range compression. In ACM transactions on graphics (TOG) (Vol. 21, No. 3, pp. 249-256). ACM. doi: 10.1145/566654.566573 [in English].

2. Ward, Greg \& Simmons, Maryann. (2005). JPEG-HDR: a backwards-compatible, high dynamic range extension to JPEG. SIGGRAPH Courses. doi: 10.1145/1185657.1185685 [in English].

3. Ward, Greg \& Reinhard, Erik \& Debevec, Paul (2008). High dynamic range imaging \& image-based lighting. ACM SIGGRAPH 2008 classes, 1-137 [in English].

4. Banterle, F. \& Debattista, K. \& Artusi, A. \& Pattanaik, S. \& Myszkowski, K. \& Ledda, P. \& Chalmers, A. (2009). High Dynamic Range Imaging and Low Dynamic Range Expansion for Generating HDR Content. Computer Graphics Forum, 28: 2343-2367. doi: 10.1111/j.1467-8659.2009.01541.x [in English].

5. Jakubiec, J. Alstan, et al. (2016). Accurate measurement of daylit interior scenes using high dynamic range photography. Proceedings of the CIE 2016 Lighting Quality and Energy Efficiency Conference. Retrieved from https://www.researchgate.net/publication/305703131 [in English].

6. Kolomiiets, O. V. (2016). Doslidzhennia tendentsii rozvytku tekhnolohii stvorennia HDR-zobrazhen. Proceedings of the Drukarstvo Molode Conference, 65-66. Kyiv: Igor Sikorsky Kyiv Polytechnic Institute [in Ukrainian].

7. Zorenko, Ya. V. \& Sak, D. O. (2014). Parametry videosystemy KVS dlia protsesu kalibruvannia. Journal of Tekhnolohiia i tekhnika drukarstva, 1(43), 21-29. Retrieved from http://ttdruk.vpi.kpi.ua/article/view/31417 [in Ukrainian].

8. Slobodian, M. O. \& Zorenko, O. V. \& Baidak, O. Yu. (2015). Profiliuvannia drukuvalnykh prystroiv dlia pidvyshchennia yakosti kolorovidtvorennia. Journal of Tekhnolohiia i tekhnika drukarstva, 1 (47), 48-60. Retrieved from http://ttdruk.vpi.kpi.ua/article/view/43275 [in Ukrainian].

9. Zorenko, O. V. \& Kyrychenko, K. H. \& Skyba, V. M. (2014). Stabilizatsiia protsesu drukuvannia zhurnalnoi produktsii. Journal of Tekhnolohiia i tekhnika drukarstva, 2(44), 35-58. Retrieved from http://ttdruk.vpi.kpi.ua/article/view/ $\underline{31819}$ [in Ukrainian].

10. Artyushina, I. L. \& Akhtariev, R. Zh. \& Vinokur, A. I. (2009). Metody registratsii i vosproizvedeniya vysokokontrastnykh originalov $v$ sistemakh $\mathrm{s}$ ogranichennym dinamicheskim diapazonom. Journal of Tekhnolohiia i tekhnika drukarstva, 3(25), 24-30. Retrieved from http://ttdruk.vpi.kpi.ua/article/view/ $\underline{57894}$ [in Russian].

11. Photoshop User Guide. Adobe Camera Raw. Adobe Help. Retrieved from https://helpx.adobe.com/ua/photoshop/user-guide.html?topic=/ua/uk/photoshop/morehelp/camera_raw [in English].

\section{В представленной работе рассматривается проблематика процесса подготовки изображений с расширенным}


диапазоном (от англ. High Dynamic Range, HDR) для размещения на веб-сайтах. Как известно, для обеспечения нормального функционирования веб-сайтов необходимо учитывать влияние большого объема информативности изображений с расширенным динамическим диапазоном. Поэтому проведенные в работе исследования HDR-технологий актуальны и позволят определить рациональное отношение визуального качества к информативности цифровых изображений, а также повысить функциональность веб-сайтов с HDR-фотографиями.

Ключевые слова: фотосайт; HDR; контраст изображения; веб-сайт; RAW; DNG; динамический диапазон.

This work investigate the problem of the process of preparing high-dynamic range images (HDR-image) for hosting on websites. The proper functioning of websites it is necessary to take into account the effect of the large volume of HDR-image information. Therefore, the result of present research work will allow to determine the rational values of visual quality and file size of digital images, as well as to enhance the functionality of websites with HDR-image.

Keywords: photo site; HDR; image contrast; web; RAW; DNG; dynamic range.

Рецензент - А. І. Іванко, к.т.н., доцент, КПІ ім. Ігоря Сікорського 